\title{
LA ESPECIAL TRASCENDENCIA CONSTITUCIONAL DE LAS DEMANDAS DE AMPARO. ANÁLISIS DE LA DOCTRINA DEL TRIBUNAL CONSTITUCIONAL SOBRE UN CONCEPTO ETÉREO
}

\section{Special Constitutional Relevance of Individual Appeals. Analysis of the Jurisprudence of the Spanish Constitutional Court Regarding an Ethereal Concept}

\author{
MARKUS GONZÁLEZ BEILFUSS \\ Universidad de Barcelona
}

Cómo citar/Citation

González Beilfuss, M. (2016)

La especial trascendencia constitucional de las demandas de amparo. Análisis de la doctrina del Tribunal Constitucional sobre un concepto etéreo Revista Española de Derecho Constitucional, 107, 333-367. doi: http://dx.doi.org/10.18042/cepc/redc.107.10

\section{Resumen}

El artículo analiza cómo se ha aplicado en la práctica el requisito de la especial trascendencia constitucional de las demandas de amparo introducido en 2007 en la Ley Orgánica del Tribunal Constitucional. A partir de las estadísticas jurisdiccionales y del análisis de las más de doscientas ocasiones en que el Tribunal Constitucional se ha pronunciado sobre este requisito, se ofrece un estudio evolutivo de cómo se ha interpretado y aplicado el nuevo régimen de admisión de las demandas de amparo constitucional. Ello permite poner de relieve que el Tribunal Constitucional ha aprovechado la reforma para acabar con la bolsa de amparos pendientes, pero no para administrarla desde una concepción más objetiva y constitucional del amparo.

\section{Palabras clave}

Recurso de amparo; Tribunal Constitucional; especial trascendencia constitucional; derechos fundamentales. 


\section{Abstract}

The article analyses how the new requirement of the special constitutional relevance of individual appeals has been implemented since it was introduced in 2007. Based on statistical data and on more than 200 decisions in which the Constitutional Court has referred to the new requirement, this study offers a diachronic overview about how the new admission system of constitutional complaints has been used. It comes to the conclusion that the Constitutional Court has used the reform to put an end to the important amount of pending cases, but not to implement it from a more objective and constitutional conception of individual appeals.

Key words

Individual appeal; constitutional complaint; Constitutional Court; special constitutional relevance; fundamental rights. 


\section{SUMARIO}

I. INTRODUCCIÓN. II. EL CONCEPTO LEGAL DE ESPECIAL TRASCENDENCIA CONSTITUCIONAL. III. ALGUNOS DATOS ESTADÍSTICOS SOBRE LAS CONSECUENCIAS DEL NUEVO RÉGIMEN DE ADMISIÓN. IV. LOS PRONUNCIAMIENTOS GENERALES DEL TRIBUNAL EN TORNO A LA ESPECIAL TRASCENDENCIA CONSTITUCIONAL: 1. Los Autos 188/2008, de 21 de julio, y 289/2008, de 22 de septiembre. 2. La Sentencia 155/2009, de 25 de junio. V. LA APLICACIÓN DE LA DOCTRINA JURISPRUDENCIAL SOBRE LA ESPECIAL TRASCENDENCIA CONSTITUCIONAL: 1. La carga de justificar la especial trascendencia constitucional. 2. El contenido material de la especial trascendencia constitucional. 3. El papel de la verosimilitud de la lesión aducida. VI. CONCLUSIONES. BibLIOGRAFía.

\section{INTRODUCCIÓN}

La reforma de la Ley Orgánica del Tribunal Constitucional del año 2007 modificó de manera importante el régimen jurídico del recurso de amparo al introducir un nuevo requisito de admisión: la especial trascendencia constitucional de las demandas de amparo. Como es sabido, de este modo se pretendía agilizar el procedimiento de admisión y reordenar la dedicación del Tribunal a sus diversas funciones ${ }^{1}$. La reforma no limitó la llegada de nuevas demandas de amparo, sino que restringió su admisión y facilitó la salida liminar de los recursos que carezcan de especial trascendencia constitucional.

Desde un principio surgieron dudas acerca del alcance de la reforma, su eficacia, su encaje constitucional, así como sus efectos sobre la tutela jurisdiccional de los derechos fundamentales ${ }^{2}$. Algunos autores también pusieron de relieve que la reforma no había abordado de manera directa el problema de la calidad de las demandas de amparo, esto es, de los muy numerosos recursos que en el fondo no plantean problemas de vulneración de derechos funda-

1 Vid. la Exposición de Motivos de la Ley Orgánica 6/2007, de 24 de mayo, por la que se modifica la Ley Orgánica 2/1979, de 3 de octubre, del Tribunal Constitucional.

2 Vid., con carácter general, las opiniones expuestas en Carrillo (2008), así como las respuestas a la Encuesta sobre la Reforma de la Ley Orgánica del Tribunal Constitucional publicada en el núm. 18 de Teoría y Realidad Constitucional en 2006. 
mentales, sino de legalidad ordinaria o discrepancias con decisiones judiciales previas $^{3}$. En todo caso, la de 2007 ha sido, sin duda, la reforma más importante en los más de treinta y cinco años de jurisdicción constitucional de amparo.

Transcurridos más de ocho años desde la entrada en vigor de esta reforma, cabe preguntarse por sus resultados. El tiempo transcurrido ya es suficiente, en efecto, para analizarlos teniendo en cuenta no solo las estadísticas jurisdiccionales, sino también las resoluciones del Tribunal Constitucional que han aplicado el nuevo régimen de admisión. Además, hay que tener en cuenta que los estudios doctrinales publicados hasta ahora se han centrado en el análisis dogmático de la reforma y en su aplicación inicial ${ }^{4}$, y que los trabajos que incorporan una reflexión sobre la aplicación real del nuevo régimen de admisión del recurso de amparo durante todos estos años con muy escasos 5 .

Si bien el contenido de la reforma del año 2007 es conocido, conviene iniciar este trabajo recordando los aspectos más importantes del concepto de especial trascendencia constitucional contenido en la Ley Orgánica del Tribunal Constitucional. Más allá de la vinculación del Tribunal a su Ley Orgánica, debe tenerse en cuenta, como se verá, que el Tribunal no fue ajeno a la reforma y que, desde un principio, tomó decisiones organizativas y de política jurisdiccional para aplicarla.

Tras este recordatorio, se expondrán algunos resultados cuantitativos de la reforma extraídos de las estadísticas que ofrecen las memorias anuales del Tribunal Constitucional. Partir de estos datos permitirá, en efecto, comprobar hasta qué punto se han cumplido algunos de los propósitos de la reforma.

Expuestas las estadísticas, será el momento de analizar cómo el Tribunal Constitucional ha ido interpretando y aplicando el nuevo régimen de admisión de los recursos de amparo. Se recordarán los pronunciamientos generales del Tribunal que han pretendido dar a conocer su doctrina y, sobre todo, se expondrá cuál está siendo la aplicación concreta de dicha doctrina en la práctica. Para ello se empleará un criterio diacrónico, coherente no solo con el carácter evolutivo de la jurisprudencia constitucional (como ha vuelto a poner de manifiesto la Sentencia del Tribunal Europeo de Derechos Humanos sobre

3 Vid., en este sentido, Borrajo Iniesta (2008).

4 Vid. Cabañas García (2010: 39-81), Hernández Ramos (2010: 263-283), Borrajo Iniesta y Elías Méndez (2009: 1-25).

5 Vid. Pérez Tremps (2015: 269-273 y 290-301), Urías Martínez (2014: 73-94) y González Alonso (2013: 17-40). 
el Asunto Arribas Antón ${ }^{6}$ ), sino también con los factores organizativos y de política jurisdiccional que han influido la administración del requisito de la especial trascendencia constitucional por parte del Tribunal Constitucional.

El análisis de la aplicación práctica de la reforma permitirá, por último, ofrecer una valoración sobre cuáles han sido los efectos de la reforma, sus ventajas e inconvenientes y, en definitiva, cuál está siendo el papel del Tribunal Constitucional en su administración.

\section{EL CONCEPTO LEGAL DE ESPECIAL TRASCENDENCIA CONSTITUCIONAL}

Como es sabido, la reforma del recurso de amparo del año 2007 pivotó sobre un concepto que carecía de tradición en el ordenamiento jurídico español y que tiene su origen en la Ley del Tribunal Constitucional Federal alemán, cuyo art. 93.a) contempla la grundsätzliche verfassungsrechtliche Bedeutung como uno de los requisitos de admisión de los recursos de amparo. Aunque el concepto de especial trascendencia constitucional tiene un contenido indeterminado y hetéreo en la jurisprudencia constitucional alemana, la reforma del año 2007 lo incorporó a nuestro país de forma decidida, en gran medida impulsado por el propio Tribunal Constitucional español. Así, más allá de la reiterada reclamación por parte de los diversos presidentes del Tribunal Constitucional de una reforma del recurso de amparo que evitase el colapso del Tribunal, la introducción del requisito de la especial trascendencia constitucional fue propuesta por el propio Tribunal e incorporada al Anteproyecto de Ley elaborado en el año 2005 por el Ministerio de Justicia. A pesar de tratarse de un concepto nuevo y de consecuencias notables, la tramitación parlamentaria no introdujo ningún cambio en él ${ }^{7}$. El legislador orgánico se limitó, pues, a dar el visto bueno a unos preceptos (los actuales arts. 49.1, 50.1 y 50.3 LOTC) que fueron gestados en el seno del Tribunal Constitucional, que fueron aceptados por el Gobierno y que en el debate

6 Tribunal Europeo de Derechos Humanos (Sección Tercera). Sentencia de 20 de enero de 2015, 16563/11, Arribas Antón contra España.

7 Entre las enmiendas presentadas (y rechazadas) solo cabe destacar algunas: una, proponiendo la supresión de dicho requisito por la inseguridad jurídica que implicaba; otra, proponiendo la introducción del perjuicio subjetivo especialmente grave como supuesto de especial trascendencia constitucional; y otras dos, tendentes a introducir algún grado de motivación en las decisiones de inadmisión. Ninguna de ellas, sin embargo, fue aceptada. 
parlamentario fueron eclipsados por la renovación del mandato de la Presidencia del Tribunal.

Tratándose de un órgano constitucional, la participación del Tribunal Constitucional en la configuración de su ley reguladora no debería extrañar. De hecho, en algún caso (por ejemplo, en Alemania) el Tribunal Constitucional ha participado en alguna ocasión en el procedimiento legislativo que ha reformado su ley reguladora. En el caso de la Ley Orgánica 6/2007 no fue así, pero desde un punto de vista material no cabe desvincular al Tribunal Constitucional de la introducción y concreta definición legal del concepto especial trascendencia constitucional.

$\mathrm{Al}$ margen de su origen, los aspectos más importantes de este requisito que cabe recordar en su actual configuración legal son los siguientes: a) la especial trascendencia constitucional se predica del recurso (arts. 49.1 in fine y 50.1.b) LOTC) y no de cada una de las pretensiones o vulneraciones aducidas; $b$ ) dicha trascendencia se contempla como un requisito positivo de admisión que debe cumplir toda demanda de amparo [arts. 50.1.a) y b) LOTC]; c) la Ley Orgánica del Tribunal Constitucional distingue de manera clara entre la necesidad ineludible («en todo caso») de justificar dicha trascendencia en la demanda [arts. 49.1 y 50.1.a) LOTC] y la existencia real de la misma, que se contempla como requisito autónomo de admisión [art. 50.1.b) LOTC]; d) el contenido material de la especial trascendencia constitucional se vincula con la justificación de un pronunciamiento de fondo del Tribunal Constitucional y, en concreto, con los tres supuestos mencionados en el art. 50.1.b) LOTC: la importancia del recurso para la interpretación de la Constitución, para su aplicación o general eficacia, y para la determinación del contenido y alcance de los derechos fundamentales; $e$ ) finalmente, y ello no debe ser olvidado, la reforma derogó las providencias de inadmisión basadas en la carencia manifiesta de contenido constitucional contempladas en el art. 50.1.c) LOTC, que habían sido empleadas con mucha frecuencia para inadmitir recursos que tenían por objeto actuaciones que de manera clara no lesionaban ningún derecho fundamental o que planteaban problemas que no eran de constitucionalidad.

La interpretación del nuevo régimen de admisión planteó desde un principio dudas que solo podían ser resueltas por el Tribunal Constitucional. Además de promotor de la reforma, el Tribunal es el único órgano que, en efecto, puede administrarla. Los márgenes para ello son, como es sabido, muy amplios. Por un lado, por el carácter indeterminado e incluso etéreo del concepto especial trascendencia constitucional y, por otro, por el necesario engranaje de este requisito con los demás requisitos del recurso de amparo. La reforma legal del año 2007 podía, de hecho, ser interpretada y aplicada de diversas maneras. Sus efectos pues, dependían en buena medida del propio Tribunal, en cuyas 
manos estaba cambiar de manera radical la admisión del recurso de amparo o modificar apenas algunos aspectos.

Una de las cuestiones no resueltas de forma clara por la reforma fue el alcance de la objetivación del amparo. La introducción del requisito de la especial trascendencia constitucional supuso, sin duda, una objetivación del recurso de amparo al excluir en fase de admisión las vulneraciones de derechos fundamentales que no tengan tal relevancia. De hecho, la vinculación del recurso de amparo con la tutela de estos derechos suscitó, como se recordará, algunas dudas en torno a la propia constitucionalidad de la reforma. Aunque estas dudas no fueron trasladadas al Tribunal Constitucional con ocasión de la impugnación de la reforma, el reconocimiento claro, en la STC 49/2008, de 9 de abril, de la libertad de configuración del autor de la Ley Orgánica del Tribunal Constitucional y de los límites al alcance del control de esta Ley por parte del Tribunal contribuye a contrarrestar tales dudas.

Al mismo tiempo, el rechazo de una enmienda que pretendía introducir el perjuicio subjetivo grave como supuesto de especial trascendencia constitucional $^{8}$, y la derogación de las providencias de inadmisión por carencia manifiesta de contenido constitucional parecían implicar una apuesta decidida por la objetivación del recurso de amparo y, por lo tanto, un cambio importante respecto a la regulación anterior. En todo caso, la relación entre el carácter subjetivo y el carácter objetivo del recurso de amparo tras la reforma ha sido, como se verá, uno de los aspectos más controvertidos y de mayor relevancia en su interpretación y aplicación práctica.

\section{ALGUNOS DATOS ESTADÍSTICOS SOBRE LAS CONSECUENCIAS DEL NUEVO RÉGIMEN DE ADMISIÓN}

Resulta conveniente comenzar cualquier estudio sobre los resultados de una reforma legal haciendo referencia a los datos estadísticos relativos a su aplicación. En el caso del Tribunal Constitucional ello resulta inexcusable, dada la calidad y exhaustividad de las estadísticas jurisdiccionales que desde hace años ofrecen las memorias anuales del propio Tribunal. Si bien dichas

8 En concreto, la Enmienda núm. 27 al proyecto de ley, propuesta por el Grupo Parlamentario Vasco, pretendió introducir como supuesto de especial trascendencia constitucional el «perjuicio particularmente grave» al demandante como consecuencia de la denegación de una decisión sobre el fondo, en un intento expreso de equilibrar las dimensiones objetiva y subjetiva del amparo. Vid. BOCG, Congreso de los Diputados, VIII Legislatura, Serie A, núm. 60-7, de 23 de febrero de 2006, p. 33. 
estadísticas no han hecho un seguimiento específico del impacto de la reforma del año $2007^{9}$, algunos de los datos contenidos en ellas deben ser destacados para valorar los resultados del nuevo requisito de la especial trascendencia constitucional.

Como refleja el gráfico 1, lo primero que cabe señalar es que entre los años 2006 y 2015 la demanda de amparo se ha reducido en más de un tercio, pasando de 11471 recursos de amparo ingresados a 7203 .

GRÁFICO 1. Recursos de amparo ingresados

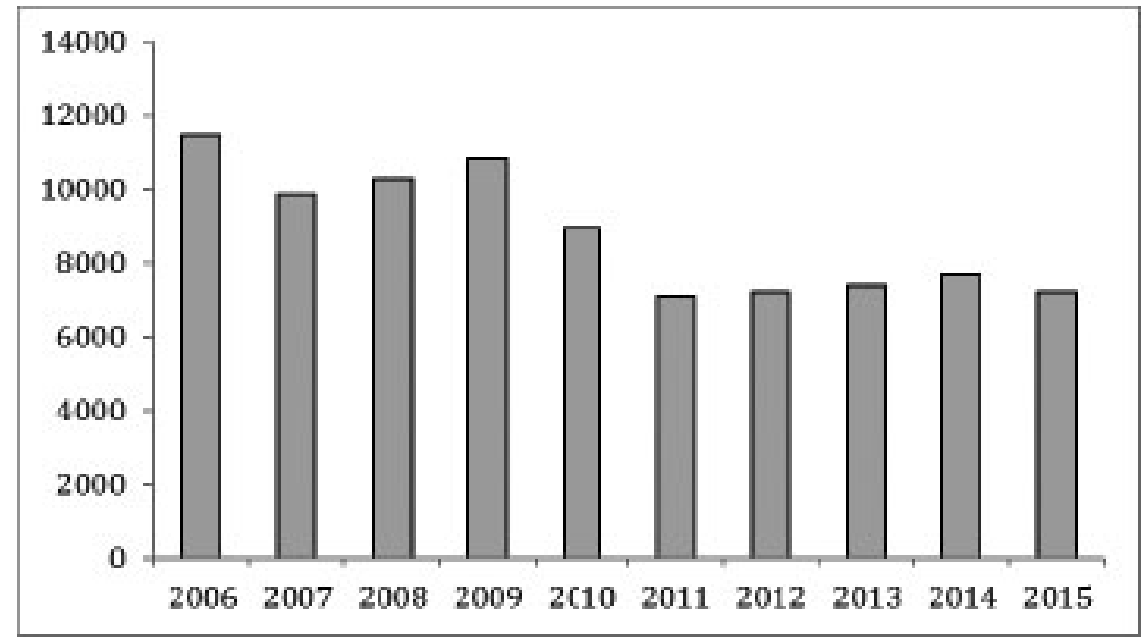

Fuente: Memorias del Tribunal Constitucional.

Si bien la reforma no limitó de manera directa la entrada de nuevos recursos, a partir del año 2010, esto es, una vez conocida la doctrina sobre la especial trascendencia constitucional contenida en la STC 155/2009, de 25 de junio, se produjo una disminución significativa de la demanda de amparo $^{10}$. Aunque este hecho está relacionado con diversos factores, no parece aventurado pensar que el requisito de la especial trascendencia constitucional

9 Las memorias de los años 2014 y 2015 incorporan, sin embargo, unos nuevos cuadros sobre los motivos de inadmisión aducidos por las providencias y sobre los supuestos en que el Tribunal Constitucional está apreciando que concurre la especial trascendencia constitucional de las demandas que, como se verá, son sumamente ilustrativos de cómo se está aplicando la reforma en la práctica.

10 Así, de los 10792 recursos de amparo ingresados en el año 2009, se pasó a los 8948 en 2010 y a los 7098 en el año 2011. 
y el modo en que el Tribunal ha gestionado en los últimos años la admisión del amparo puede haber contribuido a dicha disminución. En todo caso, una vez producida dicha reducción, en los últimos años el número de recursos de amparo se ha mantenido en torno a los $7200^{11}$.

La segunda cuestión que cabe destacar es que la introducción del requisito de la especial trascendencia constitucional no ha afectado al tipo de amparo que se demanda del Tribunal. Desde el año 2007, el porcentaje de invocación del art. $24 \mathrm{CE}$ en las demandas de amparo se mueve entre el 72 y el $88 \%$, el del art. $14 \mathrm{CE}$ entre el 13 y el $16 \%$, mientras que el de los demás derechos susceptibles de amparo se sitúa entre el 19 y el $25 \%{ }^{12}$. El recurso de amparo sigue, pues, vinculado de forma muy mayoritaria al art. $24 \mathrm{CE}$. No parece, además, que la introducción del nuevo requisito de admisión haya supuesto una mejora cualitativa de la demanda de amparo, que muchos casos sigue ocultando problemas de legalidad ordinaria o simples discrepancias con las resoluciones recurridas.

En cambio, la reforma del régimen de admisión sí ha tenido un impacto claro en el número de recursos pendientes de admisión. Como es conocido, el volumen de recursos en esta situación había crecido de forma muy significativa antes de la reforma y había alcanzando la cifra de 13883 en el año 2006. De ahí que uno de sus objetivos declarados fuese agilizar el proceso de admisión y poner fin a la enorme bolsa de recursos pendientes de admisión. Pues bien, como se desprende del gráfico 2, este objetivo se ha logrado de manera clara, al haber descendido el número de recursos de amparo pendientes de admisón a 31 de diciembre en un $76 \%$ entre los años 2006 y $2015^{13}$. Esta drástica disminución fue muy notable en 2008 , año en el que una aplicación formalista del régimen transitorio de la reforma permitió al Tribunal inadmitir por providencia un número muy elevado de recursos pendientes, lo cual hizo posible que la diferencia entre asuntos ingresados y asuntos resueltos en fase de admisión fuese negativa por primera vez en mucho tiempo ${ }^{14}$. En los

11 De hecho, entre los años 2012 y 2014 el número de recursos se incrementó, pasando de 7098 (en 2011), a 7205 (en 2012), 7376 (en 2013) y 7663 (en 2014). En 2015 el volumen de amparos ha vuelto a reducirse hasta alcanzar un total de 7203 .

12 Fuente: Memorias del Tribunal Constitucional entre los años 2006 y 2015.

13 Así, se ha pasado de 13883 recursos pendientes de admisión en 2006, a 3312 en 2015 (Fuente: Memorias del Tribunal Constitucional).

14 La disposición adicional tercera de la Ley Orgánica 6/2007 dispuso, como se recordará, que las providencias de inadmisión de los recursos anteriores a la reforma debían limitarse a expresar el supuesto en que se encontraba el recurso. Una aplicación estricta de esta disposición permitió pasar de 12166 recursos pendientes de admisión a 31 de diciembre de 2007 a 4685 un año más tarde. 
últimos años, el número de recursos de amparo pendientes de admisión ha dejado de disminuir de forma constante, de manera que en algunos años la diferencia entre asuntos ingresados y asuntos resueltos en fase de admisión ha vuelto a situarse en tasas positivas ${ }^{15}$. En todo caso, desde un punto de vista cuantitativo el efecto inmediato de la reforma ha sido la reducción del número de recursos pendientes de admisión.

GRÁFICO 2. Recursos de amparo pendientes de admisión a 31 de diciembre

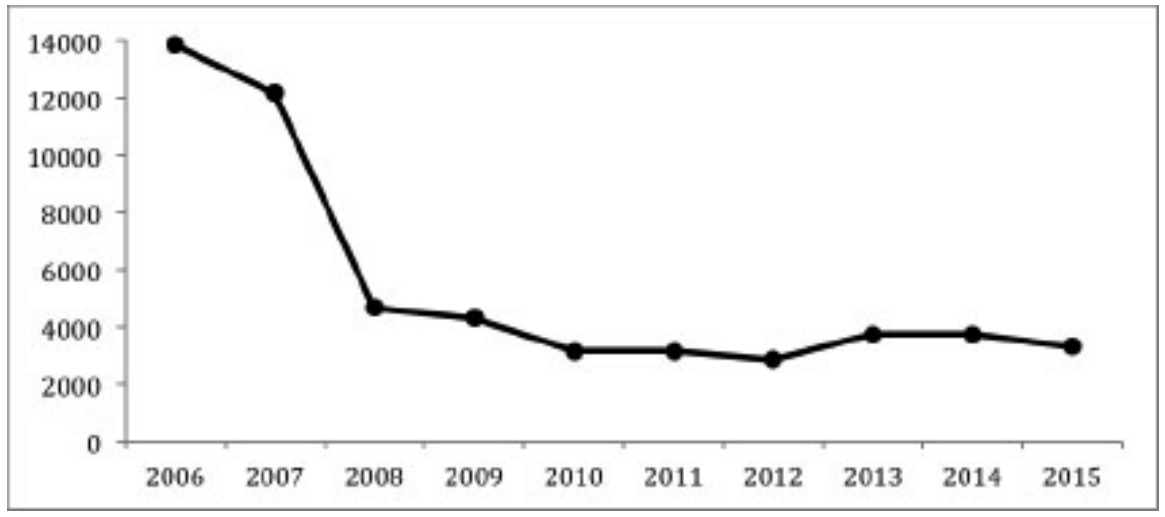

Fuente: Memorias del Tribunal Constitucional.

La disminución de los asuntos pendientes de admisión ha contribuido a alcanzar la segunda finalidad de la reforma: reordenar las funciones del Tribunal y dedicar mayor atención a las competencias que son exclusivas de este órgano. En efecto, como pone de relieve el gráfico 3, el número de recursos pendientes de sentencia a 31 de diciembre se ha reducido de manera significativa en los últimos años. En concreto, en un $68 \%$ en el caso de los recursos de amparo y en un $64 \%$ de los asuntos competencia del Pleno ${ }^{16}$. El amparo se ha puesto, pues, casi al día (88 asuntos pendientes de sentencia a 31 de diciembre de 2015), mientras que los asuntos de Pleno pendientes se han reducido de manera significativa, aunque no suficiente, puesto que en la misma fecha había 223 asuntos pendientes de sentencia.

15 Este fue el caso en los años 2011, 2013 y 2014. En el año 2015 la tasa ha vuelto a ser claramente negativa (-1299) como consecuencia de un notable aumento de las providencias de inadmisión.

16 Así, el número de recursos de amparo admitidos pendientes de sentencia ha pasado de 277 en el año 2006 a 88 en el año 2015, mientras que los asuntos competencia del Pleno han pasado de 622 a 223 en el mismo período. 
GRÁFICO 3. Asuntos de Pleno y de Sala pendientes de sentencia a 31 de diciembre

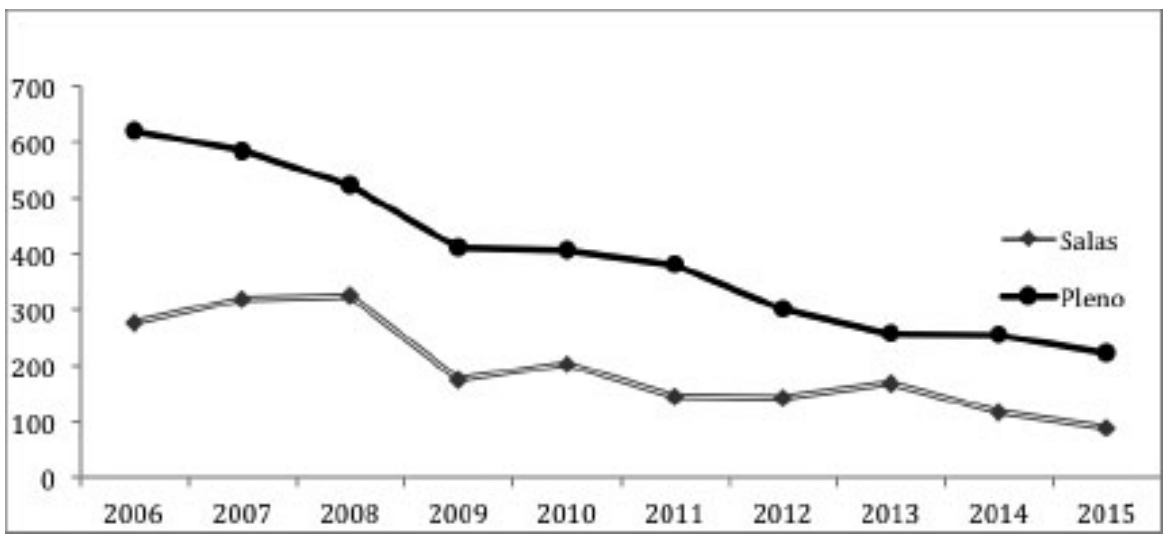

Fuente: Memorias del Tribunal Constitucional.

Los objetivos perseguidos con la reforma parecen, pues, haberse cumplido desde un punto de vista cuantitativo: la admisión a trámite de los recursos de amparo se ha agilizado y el Tribunal ha podido dedicar más tiempo y esfuerzos a los asuntos de fondo. Sin embargo, cabe preguntarse cuál ha sido el precio que se ha tenido que pagar por ello y, sobre todo, si este ha sido excesivo no solo para la demanda de amparo que estaba pendiente de admisión, sino también para la demanda futura y para la propia institución del recurso de amparo.

\section{LOS PRONUNCIAMIENTOS GENERALES DEL TRIBUNAL EN TORNO A LA ESPECIAL TRASCENDENCIA CONSTITUCIONAL}

Como es sabido, aunque la Ley Orgánica 6/2007 entró en vigor de manera inmedita, los primeros pronunciamientos jurisprudenciales sobre el nuevo régimen de admisión del recurso de amparo tuvieron que esperar casi un año. El Tribunal Constitucional decidió, en efecto, resolver primero la suerte de las casi 14000 demandas de amparo que estaban pendientes de admisión haciendo uso de la previsión contenida en la disposición adicional tercera de dicha Ley, que limitó el contenido de las providencias de inadmisión a «expresar el supuesto en el que se encuentra el recurso». A través de una expresión muy similar a la empleada en el actual art. 50.3 LOTC (que establece que dichas providencias «especificarán el requisito incumplido»), la reforma obligó de manera deliberada al Tribunal a apartarse de las prolijas 
providencias de inadmisión para dar salida a la mayor parte de recursos pendientes de admisión.

Los resultados de esta decisión de política jurisdiccional han sido analizados con detenimiento por otros autores ${ }^{17}$, de modo que no es preciso detenerse en este punto. En todo caso, sí cabe destacar que, tras adoptar algunas medidas organizativas internas, el Tribunal consiguió acabar en un año con la bolsa de admisiones pendientes y pudo dedicarse de manera exclusiva a la aplicación del nuevo régimen de admisión. Esta inaplicación de facto del nuevo régimen de admisión durante un período interino que se prolongó más de lo previsto suscitó críticas por parte de los abogados, que durante todo este tiempo recibieron providencias de inadmisión sin motivación (algo a lo que que no estaban acostumbrados) y no dispusieron de criterios jurisprudenciales sobre el contenido del nuevo régimen de admisión. En un país en que el conocimiento de la normativa vigente, la formación en asuntos constitucionales y la capacidad para interpretar conceptos indeterminados no puede darse siempre por supuesta, tales críticas no resultan extrañas. Sin embargo, el precio de esta decisión de política jurisdiccional resultó asumible, ya que sentó las bases para una aplicación ordenada de la reforma.

\section{LOS AUTOS 188/2008, DE 21 DE JULIO, Y 289/2008, DE 22 DE SEPTIEMBRE}

Eliminada la bolsa de recursos de amparo anteriores a la reforma pendientes de admisión, una segunda decisión de política jurisdiccional del Tribunal fue dar a conocer los criterios generales de interpretación del nuevo régimen de admisión. Consciente del tiempo transcurrido desde la entrada en vigor de la reforma, en el verano del año 2008 el Tribunal decidió publicar en el BOE algunas decisiones de inadmisión (a las que se dio forma de auto) que aplicaban el nuevo régimen jurídico. Así, a través de los conocidos AATC 188/2008, de 21 de julio, y 289/2008, de 22 de septiembre, las dos Salas del Tribunal establecieron una misma doctrina general sobre el requisito de la especial trascendencia constitucional que se ha mantenido casi invariable hasta la actualidad y cuyos ejes principales cabe recordar: por un lado, corresponde al recurrente justificar la especial trascendencia constitucional del recurso con una argumentación diferente de la que se dedica a la lesión del derecho fundamental invocado; por otro lado, tal carga de justificación constituye un requisito insubsanable, dada la naturaleza material de la especial trascendencia constitucional y la literalidad del art. 49.1 LOTC («en todo caso»); por último, corresponde al

17 Vid. Borrrajo Iniesta y Elías Méndez (2009: 2-6). 
Tribunal Constitucional apreciar si dicha trascendencia se da en cada caso, atendiendo a los criterios contemplados en el art. 50.1.b) LOTC.

Si bien ambos Autos se centraron en la justificación de la especial trascendencia constitucional, el Tribunal dejó claro que la pretendida lesión de un derecho fundamental sigue siendo un presupuesto inexcusable (pero distinto) de toda demanda de amparo. Sin embargo, el Tribunal no se pronunció en torno a cómo inadmitir las demandas en las que era clara la ausencia de dicha lesión, toda vez que en la nueva regulación no existe una norma equivalente al antiguo art. 50.1.c) LOTC y que no había acuerdo en el seno del propio Tribunal en torno a la posibilidad de inadmitir tales demandas con base en el art. 50.1.a) por no considerar verosímil la lesión invocada, o con base en el art. 50.1.b) LOTC, esto es, por no concurrir el requisito de la especial trascendencia constitucional.

En los primeros años de vigencia de la reforma el Tribunal dio una importancia capital al deber del recurrente de justificar la especial trascendencia constitucional del recurso. De hecho, ante el flagrante desconocimiento de la reforma por parte de un número importante de abogados, fueron muchas las providencias de inadmisión que consideraron no satisfecha la carga de justificar la especial trascendencia del recurso [art. 50 1.a) LOTC] después de realizar un control sobre todo formal de las demandas. Esta práctica suscitó tensiones en el seno del propio Tribunal Constitucional que se pusieron de manifiesto en el voto particular del magistrado Gay Montalvo al ATC $289 / 2008^{18}$. En todo caso, la aplicación práctica de dicha doctrina ha generado, como se verá, no pocos problemas relacionados con el contenido de dicha justificación y su control por parte del Tribunal.

A pesar de ello, cabe destacar que esta doctrina general en torno a la obligación del recurrente de justificar la especial trascendencia constitucional del recurso se ha mantenido casi invariable hasta nuestros días. De hecho, en relación con este requisito los únicos pronunciamientos posteriores que mere-

18 Como se recordará, en este voto particular se puso de relieve una discrepancia no con la reforma, sino con la aplicación del requisito de justificar la especial trascendencia constitucional. En opinión del magistrado discrepante, esta aplicación era demasiado rígida (sobre todo en un momento en que no había doctrina sobre el contenido de dicho concepto) en supuestos en que la trascendencia constitucional es evidente a la luz de los hechos y la argumentación de la demanda. Con posterioridad, en el ATC 28/2013, de 11 de febrero, el magistrado Valdés Dal-Ré también ha discrepado de una interpretación rigorista del deber de justificar la especial trascendencia constitucional, que se considera que puede resultar contraria a la propia doctrina del Tribunal sobre las decisiones de admisión por parte de los jueces ordinarios. 
cen ser destacados son el ATC 262/2009, de 11 de noviembre, que admite que dicha justificación se realice a través de un escrito de ampliación de la demanda presentado en plazo, el ATC 26/2012, de 31 de enero, que extiende al Ministerio Fiscal el deber de justificación cuando recurra en súplica una providencia de inadmisión, y la STC 176/2012, de 15 de octubre, que en aplicación de dicha doctrina lleva al Tribunal a rechazar la posibilidad de apreciar de oficio la concurrencia de la especial trascendencia consitucional si ésta no ha sido justificada por el recurrente. Como se verá más adelante, sin embargo, ello no significa que el rigor con el que se ha aplicado esta doctrina haya sido siempre idéntico ni que en la práctica se haya hecho un uso en algunos casos discutible e incierto de la misma.

\section{LA STC $155 / 2009$, DE 25 DE JUNIO}

En la misma línea de dar a conocer la doctrina general en torno a la especial trascendencia constitucional, casi un año después de los dos Autos que se acaban de analizar y, por lo tanto, transcurridos algo más de dos años desde la entrada en vigor de la reforma, el Tribunal aprovechó la resolución de un recurso de amparo que no planteaba especiales problemas para avocarlo al Pleno y dar a conocer la doctrina general en torno a los supuestos en que puede considerarse que concurre la especial trascendencia constitucional. Así, en el famoso fundamento jurídico 2 de la STC 155/2009, de 25 de junio, el Tribunal se pronunció por vez primera con carácter general sobre la dimensión material de dicho requisito tras un proceso de reflexión interna en el que tuvo en cuenta no solo algún caso anterior (en concreto, la STC 70/2009, de 23 de marzo), sino también determinadas experiencias de derecho comparado y, en especial, la del Tribunal Constitucional Federal alemán ${ }^{19}$, que era conocida de primera mano gracias a los encuentros bilaterales entre los dos Tribunales.

Como es de sobra conocido, el Tribunal Constitucional español enumeró y describió en dicho fundamento jurídico un total de siete supuestos de especial trascendencia constitucional que no constituyen un elenco cerrado, pero que de momento no se han modificado. Aunque su descripción es más concreta, tales supuestos pueden resumirse del siguiente modo: $a$ ) ausencia de doctrina constitucional; $b$ ) aclaración o cambio de doctrina; $c$ ) origen norma-

19 En relación con los paralelismos y diferencias entre la doctrina contenida en esta Sentencia y los criterios empleados por el Tribunal Constitucional Federal alemán, vid. Hernández Ramos (2010: 272 y ss.). 
tivo de la vulneración aducida; d) reiterada interpretación jurisprudencial de la ley lesiva de un derecho fundamental; $e$ ) incumplimiento general y reiterado de la doctrina constitucional por parte de la jurisdicción ordinaria; $f$ ) negativa manifiesta del deber de acatamiento de la doctrina constitucional; y g) relevante y general repercusión social o económica de la cuestión suscitada, o consecuencias políticas generales de la misma.

Más allá de la enumeración de estos supuestos de especial trascendencia constitucional y de los problemas que suscita su concreta delimitación, la STC 155/2009 constituye, sin duda, el pronunciamiento más importante sobre esta figura realizado hasta el momento por el Tribunal Constitucional. Por un lado, en esta Sentencia se reconoce de forma expresa que el requisito de la especial trascendencia constitucional plasma la opción del legislador por una nueva configuración del recurso de amparo, aunque este, «en todo caso, sigue siendo un recurso de tutela de derechos fundamentales». Por otro lado, en esta Sentencia también se pone de relieve que el Tribunal se considera el dueño de la especial trascendencia constitucional, en el sentido que dispone de «un amplio margen decisorio para estimar cuándo el contenido de un recurso justifica una decisión sobre el fondo en atención a su especial trascendencia constitucional», que él es el único a quien le corresponde «apreciar» en cada caso la concurrencia de este requisito. Por último, cabe recordar que la Sentencia reconoce de manera expresa que «no cabe descartar la necesidad de perfilar o depurar conceptos, redefinir supuestos contemplados, añadir otros nuevos o excluir alguno» de los incluidos inicialmente en su fundamento jurídico 2.

En definitiva, queda claro que los destinatarios de este pronunciamiento fueron los demandantes de amparo y no el propio Tribunal Constitucional, que puede modificarlo en cualquier momento. La posibilidad de cambiar los supuestos de especial trascendencia constitucional no significa, sin embargo, que el Tribunal pueda hacer una aplicación de su doctrina que se aparte en el fondo de esta o que no garantice ciertos niveles de certidumbre y seguridad jurídica. Esto es, de hecho, lo que ha puesto de manifiesto el Tribunal Europeo de Derechos Humanos en la Sentencia del Asunto Arribas Antón contra España, en la que ha concluído que el respeto al principio de seguridad jurídica no solo obliga al Tribunal Constitucional a «definir el contenido y alcance del criterio de la especial trascendencia constitucional», sino también a «explicitar su aplicación en los asuntos declarados admisibles con el fin de garantizar una buena administración de justicia» ${ }^{20}$. Aunque este pronunciamiento ha venido a avalar que el nuevo régimen de admisión no vulnera el

$20 \$ 46$ de la Sentencia de la Sección Tercera del Tribunal Europeo de Derechos Humanos, de 20 de enero de 2015 (16563/11). 
Convenio Europeo de Derechos Humanos ${ }^{21}$, dichas exigencias de seguridad jurídica han llevado al Tribunal Constitucional, como se verá, a cambiar el modo en que está aplicando su propia doctrina sobre la especial trascendencia constitucional. En todo caso, lo que ha puesto de manifiesto la Sentencia del Tribunal Europeo de Derechos Humanos es que el modo de aplicar el requisito de la especial trascendencia constitucional de las demandas de amparo tiene — valga la redundancia — una dimensión constitucional clara.

\section{LA APLICACIÓN DE LA DOCTRINA JURISPRUDENCIAL SOBRE LA ESPECIAL TRASCENDENCIA CONSTITUCIONAL}

Expuestas las líneas generales de la doctrina desarrollada por el Tribunal Constitucional en torno a este nuevo requisito de admisión, cabe preguntarse cuál ha sido su aplicación concreta durante los años sucesivos. Así, el positivo - aunque seguramente tardío- esfuerzo del Tribunal por concretar una figura que no le era ajena debe ser contrastado con la actividad cotidiana del Tribunal apreciando si se han cumplido los requisitos relacionados con la especial trascendencia constitucional de las demandas de amparo. Solo de este modo, en efecto, es posible valorar cuáles han sido los efectos reales de la reforma y hasta qué punto se ha modificado el comportamiento del Tribunal en la fase de admisión de los recursos de amparo.

Conocer cuál ha sido la aplicación real de la doctrina sobre la especial trascendencia no es fácil, teniendo en cuenta el régimen jurídico de los pronunciamientos de admisión de los recursos de amparo. Como es sabido, en el caso de las providencias de inadmisión la reforma del año 2007 introdujo la previsión de que estas «especificarán el requisito incumplido» (art. 50.3 LOTC) para acabar de este modo con las prolijas explicaciones contenidas en las providencias basadas en el antiguo art. 50.1.c) LOTC. Por su parte, las

21 Cabe señalar que el Tribunal Europeo de Derechos Humanos ya había desestimado en anteriores pronunciamientos recursos planteados contra providencias de inadmisión derivadas de la Ley Orgánica 6/2007. Así, en el Asunto Almenara Álvarez contra España, núm. 16096/98, de 25 de octubre de 2011, el Tribunal había rechazado que una providencia de inadmisión de un recurso planteado antes de la reforma careciese de motivación y fuese arbitraria por limitarse a afirmar que la demanda carecía de contenido constitucional. Por su parte, en el Asunto Rupprecht contra España, núm. $38471 / 10$, de 19 de febrero de 2013, el Tribunal había rechazado que una providencia de inadmisión basada en la no justificación de la especial trascendencia constitucional fuese contraria al derecho a un recurso efectivo. 
providencias de admisión siempre se han limitado a decidir la admisión del recurso sin necesidad de justificar ni especificar la razón para ello. El problema para conocer cómo se está aplicando el nuevo régimen de admisión no deriva, pues, solo de la falta de publicidad de las providencias, sino sobre todo de su contenido.

Para conocer el modo en que se está aplicando el requisito de la especial trascendencia constitucional solo cabe acudir, por lo tanto, a dos tipos de pronunciamientos del Tribunal: las sentencias de amparo en que el debate sobre este requisito se plantea como óbice procesal y los autos que dan respuesta a los recursos de súplica interpuestos por el Ministerio Fiscal por discrepar del criterio mantenido por las Secciones en torno a la no concurrencia del mismo (art. 50.3 LOTC). A estas dos fuentes de conocimiento cabe añadir, desde hace poco, los pronunciamientos sobre la especial trascendencia constitucional que están empezando a generalizarse como consecuencia de la Sentencia del Tribunal Europeo de Derechos Humanos sobre el Asunto Arribas Antón contra España ${ }^{22}$. En efecto, como se verá más adelante, a raíz de esta Sentencia el Tribunal Constitucional está pronunciándose con mucha mayor frecuencia sobre el motivo concreto que justifica la concurrencia de la especial trascendencia constitucional de la demanda.

En contra de lo que cabría esperar, este material no es escaso; así, desde la entrada en vigor de la reforma y hasta el 31 de diciembre de 2015 el Tribunal se ha pronunciado de forma expresa sobre el requisito de la especial trascendencia constitucional en 239 ocasiones (152 sentencias y 87 autos) ${ }^{23}$. El problema no es, pues, cuantitativo, sino cualitativo, puesto que los pronunciamientos del Tribunal suelen ser parcos y poco fundamentados. Este último hecho es en buena medida lógico, teniendo en cuenta que la actual Ley Orgánica se refiere a la necesidad de «apreciar» la concurrencia de la especial trascendencia constitucional o de «especificar» el incumplimiento de este nuevo requisito de admisión. La reciente jurisprudencia del Tribunal Europeo de Derechos Humanos tampoco parece haber provocado un cambio significativo desde este punto de vista, puesto que el Tribunal Constitucional suele limi-

22 El propio Tribunal Constitucional ha llegado a calificar la doctrina del Tribunal Europeo de exigencia (STC 239/2015, de 30 de noviembre, FJ 2) y la ha seguido en bastantes, aunque no todos los casos (vid., a modo de ejemplo, las SSTC 181, 182 y 183/2015, de 7 de septiembre; 187/2015, de 10 de septiembre; 194 y 195/2015, de 21 de septiembre, y 232/2015, de 5 de noviembre).

23 La existencia de familias de asuntos y las referencias más bien formales a dicho requisito reducen a unos 130 los pronunciamientos relevantes desde un punto de vista material. 
tarse a hacer una breve referencia al supuesto del fundamento jurídico 2 de la STC 155/2009 que considera aplicable.

En cualquier caso, el análisis de los pronunciamientos del Tribunal sobre el requisito de la especial trascendencia constitucional pone de manifiesto que la aplicación de la doctrina constitucional ha planteado problemas relacionados con la seguridad jurídica y, por seguir el criterio del Tribunal de Estrasburgo, la buena administración de justicia que deberían ser evitados.

\section{LA CARGA DE JUSTIFICAR LA ESPECIAL TRASCENDENCIA CONSTITUCIONAL}

Como se ha visto en la páginas anteriores, el Tribunal Constitucional ha insistido desde un principio en la necesidad de que el recurrente justifique, en todo caso, la especial trascendencia constitucional de su demanda como algo distinto a la vulneración del derecho fundamental aducida. La doctrina sobre esta carga no ha sufrido cambios significativos desde la entrada en vigor de la reforma, pero su contenido concreto y el rigor con que se ha aplicado sí han variado, lo que ha generado en ocasiones una notable inseguridad jurídica.

Así, en los primeros años de vigencia de este nuevo requisito, el Tribunal hizo una interpretación formalista del deber de justificar la especial trascendencia constitucional. En efecto, influido por una demanda de amparo que en muchas ocasiones no se había adaptado al nuevo régimen de admisión, así como por el propósito de dedicar sus esfuerzos a la resolución de los problemas de fondo, el Tribunal dio importancia a criterios formales como la mención expresa del concepto especial trascendencia constitucional o la existencia de un apartado específico en la demanda dedicado a dicho concepto. Pero, además, en esta primera fase se emplearon criterios distintos para considerar cumplida la carga de justificar la especial trascendencia constitucional de una demanda. Basta remitirse a la lectura de los trece autos del año 2009 que estimaron los recursos de súplica interpuestos por el Ministerio Fiscal contra providencias de inadmisión que habían considerado incumplida dicha carga ${ }^{24}$. El empleo de criterios diferentes era en parte lógico, teniendo en cuenta la novedad de la reforma y las dificultades que plantea un control formal que siempre es de suficiencia. Pero, en el fondo, lo que originó a tales diferencias

24 AATC 61 y 62/2009, de 23 de febrero; 92/2009, de 18 de marzo; 149, 150 y 151/2009, de 14 de mayo; 164/2009, de 22 de mayo; 166/2009, de 27 de mayo; 179/2009, de 10 de junio; 182 y 183/2009, de 15 de junio; 187/2009, de 22 de junio; y 283/2009, de 17 de diciembre. 
fueron sobre todo las discrepancias entre los propios magistrados sobre el papel que cabía otorgar a la lesión aducida, que para algunos no podía dejar de atenderse por una insuficiente justificación de su especial trascendencia constitucional ${ }^{25}$.

Como es lógico, la existencia de criterios dispares en torno a este requisito suscitó problemas de inseguridad jurídica difíciles de justificar. Probablemente consciente de ello, en los últimos años el Tribunal Constitucional ha reconocido de forma expresa la necesidad de emplear un nivel de exigencia distinto en relación con la carga de justificar la especial trascendencia constitucional en función de si la demanda de amparo se planteó antes o después de la STC 155/2009 26 . En este mismo sentido, la flexibilización de dicho deber también le ha llevado a admitir (en contra de lo practicado en otros momentos) que no es preciso ni emplear la expresión especial trascendencia constitucional ni dedicar un apartado específico a su justificación para considerar cumplido dicho deber ${ }^{27}$, siendo suficiente un «esfuerzo argumental razonable» en relación con el mismo ${ }^{28}$. En todo caso, como ha reconocido el propio Tribunal $^{29}$, la flexibilización del deber de justificar la especial trascendencia constitucional no es absoluta ni puede llevarlo a apreciar de oficio su concurrencia cuando no ha sido justificada.

Esta relativización de la carga de justificar la especial trascendencia constitucional ha sido relacionada por el propio Tribunal con el carácter instrumental de la demanda de amparo, que es un instrumento de colaboración con la jurisdicción constitucional ${ }^{30}$. El Tribunal es, en efecto, quien aprecia la concurrencia de la especial trascendencia constitucional sin estar condicionado por la demanda, aunque el esfuerzo del recurrente para justificarla puede serle de utilidad. En todo caso, esta flexibilización de la dimensión formal de la especial trascendencia consitucional no ha hecho desaparecer los problemas de inseguridad jurídica de los primeros años. Lo que constituya, en efecto, un

25 Vid., en este sentido, el ya mencionado voto particular del magistrado Gay Montalvo al ATC 289/2008, de 22 de septiembre.

26 Vid., entre otras, la STC 15/2011, de 28 de febrero, en la que con remisión a algunos autos anteriores se defiende la utilización de un nivel de rigor inferior en relación con las demandas anteriores a dicha Sentencia.

27 Vid., en este sentido, las SSTC 176/2012, de 15 de octubre, y 118/2014, de 8 de julio.

28 Vid., las SSTC 89/2014, de 9 de junio, y 88/2015, de 11 de mayo.

29 Vid., las SSTC 143/2011, de 26 de septiembre; 176/2012, de 15 de noviembre, y 87/2015, de 18 de mayo.

30 Vid., en este sentido, la STC 60/2015, de 14 de julio. 
«esfuerzo argumental razonable» para justificarla sigue siendo un juicio de suficiencia de contenido incierto y en no pocos casos discutible ${ }^{31}$.

Al margen de ello, el análisis de la aplicación de este requisito formal pone de relieve que la influencia de la dimensión material de la especial trascendencia constitucional y, sobre todo, de la verosimilitud de la lesión aducida es muy importante en la práctica. Como se verá más adelante, lo que en algún pronunciamiento inicial constituyó un argumento adicional para inadmitir un recurso (la lesión aducida era inverosímil) ${ }^{32}$ se ha convertido en un criterio de decisión material que lleva al Tribunal a admitir a trámite recursos en los que la justificación de la trascendencia constitucional es deficiente. Solo desde este modo, en efecto, cabe interpretar algunos pronunciamientos del Tribunal que aprecian sin apenas motivación la especial trascendencia constitucional de la demanda cuando de los antecedentes se desprende que apenas había sido justificada por el recurrente, o que relajan el nivel de exigencia cuando se está ante una lesión más verosímil e importante. Este es el caso, por ejemplo, de algunas sentencias que han querido dar respuesta, al margen de la insuficiente justificación de la especial trascendencia constitucional, a demadas de amparo planteadas contra inadmisiones a limine de habeas corpus o contra inadmisiones de incidentes de nulidad de actuaciones en supuestos en que tales incidentes eran el único remedio posible para reparar la vulneración del art. $24 \mathrm{CE}^{33}$.

Más allá de los supuestos en que la lesión resulta verosímil, la jurisprudencia del Tribunal Constitucional también destaca que la carga de justificar la especial trascendencia constitucional de una demanda se relativiza en los supuestos en que la vulneración del derecho fundamental deriva de un precepto legal ${ }^{34}$, así como en el caso de los recursos de amparo parlamentarios o electorales, en los que dicha carga se da casi por satisfecha. La aplicación de la

31 Prueba de ello son los recursos de súplica que sigue planteando el Ministerio Fiscal en los que discrepa del parecer del Tribunal. Si bien son menos frecuentes que en los primeros años, siguen presentándose recursos contra el criterio mantenido por el Tribunal, que, en algunos, casos son estimados por haberse considerado de manera errónea que no se había justificado dicha trascendencia de modo suficiente. Vid., en este sentido, el ATC 108/2014, de 7 de abril.

32 Vid., en este sentido, el ATC 80/2009, de 9 de marzo.

33 En relación con el primer supuesto, vid. la STC 195/2014, de 1 de diciembre. En relación con el segundo supuesto, vid., entre otras, las SSTC 96/2015, de 25 de mayo; $115 / 2015$, de 8 de junio; y 169/2015, de 20 de julio.

34 Vid., por ejemplo, la STC 118/2014, de 8 de julio, que resuelve un recurso en el que ni siquiera se hacía alusión a la especial trascendencia constitucional, pero en el que sí se había puesto de relieve que la vulneración podía provenir de una norma con rango de ley. 
doctrina del Tribunal está poniendo de relieve, pues, no solo la utilización de diversas intensidades de control de la carga de justificar la especial trascendencia constitucional, sino que la verosimilitud de la lesión aducida y la dimensión material de la especial trascendencia constitucional están teniendo un peso decisivo en la práctica.

Por último, cabe destacar que las estadísticas del Tribunal Constitucional recalcan que la dimensión formal de la especial trascendencia constitucional está ocupando un lugar muy destacado en la jurisprudencia constitucional. Así, en los años 2014 y 2015 más del $30 \%$ de las providencias de inadmisión se han basado en la ausencia o en la insuficiencia de la justificación ducida, mientras que menos del $1 \%$ de las inadmisiones se han fundamentado en la falta material de especial trascendencia constitucional. ${ }^{35} \mathrm{El}$ Tribunal Constitucional parece sentirse más cómodo, pues, con la dimensión formal de este nuevo requisito, a pesar de que su aplicación ha planteado no pocos problemas. Si bien en un primer momento podía ser razonable inisistir en la necesidad de justificar la especial trascendencia constitucional como un mecanismo para reforzar el nuevo régimen de admisión, seguir otorgando un papel preponderante a la carga de justificar dicha especial trascendencia se compadece mal con una jurisdicción constitucional que asume sus funciones y decide qué asuntos merecen su atención. En este mismo sentido, debe advertirse sobre la posibilidad que el Tribunal no quiera admitir a trámite recursos de amparo incómodos o polémicos con el simple argumento de que no se ha justificado de manera suficiente su especial trascendencia constitucional $^{36}$.

\section{EL CONTENIDO MATERIAL DE LA ESPECIAL TRASCENDENCIA CONSTITUCIONAL}

Frente al protagonismo otorgado a la carga de justificar la especial trascendencia constitucional de las demandas, el contenido material de dicha trascendencia ha ocupado un papel mucho menos relevante en los pronuncia-

35 En concreto, en el año 2014, el 19,97 \% de las providencias de inadmisión se basaron en la falta de justificación de la especial trascendencia constitucional y el 16,27 \%, en la insuficiente justificación, mientras que solo en el 0,25\% de los recursos se consideró que no concurría un supuesto material de especial trascendencia constitucional. En el año 2015, los porcentajes han sido del 16,67, 19,60 y 0,78, respectivamente. Fuente: Memorias del Tribunal Constitucional de los años 2014 y 2015.

36 Vid., en este sentido, Urias Martínez (2014: 87 y ss.). 
mientos del Tribunal de los últimos años. Así, hasta la STC 155/2009, de 25 de junio, el Tribunal apenas se limitó a reproducir los criterios señalados en el art. 50.1.b) LOTC en relación con este concepto. Con posterioridad, la doctrina sobre la carga de justificar la especial trascendencia constitucional de la demanda mediante su conexión con alguna de las letras del FJ 2 de dicha Sentencia llevó al Tribunal a pronunciarse con más frecuencia sobre la concurrencia material de dicho requisito. Pero ha sido la Sentencia del Tribunal Europeo Arribas Antón contra España la que está propiciando pronunciamientos generalizados sobre el concreto supuesto que motiva la especial trascendencia constitucional de las demandas de amparo.

En todo caso y como ya se ha avanzado, los pronunciamientos del Tribunal sobre esta cuestión acostumbran a ser parcos y, por lo general, se limitan a referirse a una o varias de las letras del FJ 2 de la STC 155/2009 ${ }^{37}$. A pesar de que, como se ha reconocido de forma expresa ${ }^{38}$, el concepto que nos ocupa tiene un carácter abierto, flexible e indeterminado, el Tribunal no se ha sentido, por lo general, obligado a justificar con detalle ni la concurrencia de dicha trascendencia ni el supuesto concreto de dicho fundamento jurídico en que se basaba ${ }^{39}$. En tanto dueño de la especial trascendencia constitucional, el Tribunal se ha limitado, pues, a apreciar su concurrencia. En todo caso, el análisis de las resoluciones que se han pronunciado al respecto permite poner de manifiesto algunas cuestiones que merece la pena destacar ${ }^{40}$.

Así, el supuesto contemplado en la letra a) del fundamento jurídico 2 de la STC 155/2009 (que el recurso "plantee un problema o una faceta de un derecho fundamental susceptible de amparo sobre el que no haya doctrina del Tribunal Constitucional») está siendo de manera clara el más invocado en la práctica. A pesar de que en treinta y cuatro años de actividad el Tribunal ha tenido ocasión de crear jurisprudencia en casi todos los ámbitos, este supuesto

37 Antes del pronunciamiento del Tribunal de Estrasburgo, en algunos casos el Tribunal Constitucional también se limitó a señalar que no se apreciaba la necesidad de modificar la decisión inicial de inadmisión (vid., por ejemplo, la STC 127/2013, de 3 de junio).

38 Vid., las SSTC 118/2014, de 8 de julio, y 77/2015, de 27 de abril.

39 Vid., a modo de ejemplo, los AATC 61/2010, de 31 de mayo; 96/2010, de 19 de julio; 185/2010, de 29 de noviembre; y 201/2010, de 21 de diciembre, así como la STC 89/2011, de 6 de junio.

40 La Memoria del Tribunal Constitucional del año 2015 ha incorporado por vez primera información estadística sobre los diversos motivos de especial trascendencia constitucional apreciados por el Tribunal (vid. cuadro 15), aunque en algunos casos la información ofrecida no se corresponde de manera exacta con los supuestos enumerados en la STC 155/2009. 
de especial trascendencia constitucional se ha esgrimido en más de 25 ocasiones (un 22,98\% de supuestos en el año $2015^{41}$ ). El Tribunal ha aclarado que la ausencia de doctrina se refiere al momento de interposición del recurso y no al de su admisión o resolución ${ }^{42}$. Pero, en todo caso, ha hecho una interpretación generosa de este supuesto, en el sentido de considerar que no hace falta que no exista una doctrina sobre un derecho fundamental o una faceta de este, sino que basta con que se plantee una cuestión concreta nueva. Así por ejemplo, las condiciones que deben darse para que la policía pueda acceder a la agenda de un teléfono móvil, la posibilidad de sancionar al propietario de un vehículo por no identificar al conductor o las facultades empresariales de controlar el correo electrónico de los trabajadores han sido considerados supuestos nuevos sobre los que no existía una jurisprudencia previa ${ }^{43}$. En algunos de estos casos puede discutirse si existe una ausencia de doctrina o si lo que en realidad se pretende es aclarar algún extremo de esta ${ }^{44}$. Pero el sentido que el Tribunal acostumbra a dar al concepto doctrina constitucional (más vinculado a precedente que a normas subconstitucionales derivadas de la actividad del Tribunal) ha tenido como consecuencia una aplicación muy generosa del primer supuesto de especial trascendencia constitucional contemplado en la STC $155 / 2009$.

Por su parte, el supuesto de la letra b) (aclaración o cambio de la doctrina constitucional) también ha sido apreciado por el Tribunal de forma frecuente, sobre todo en los últimos años. Así, en el año 2015 un 27,57 \% de los recursos de amparo admitidos a trámite se fundamentaron en este supuesto de especial trascendencia constitucional ${ }^{45}$. De los 22 casos en que el Tribunal ha considerado que concurría este supuesto, en ninguno se ha hecho alusión a la necesidad de acoger la jurisprudencia del Tribunal Europeo de Derechos Humanos. En general, el Tribunal tampoco acostumbra a indicar de forma clara si el posible cambio de doctrina obedece a un un proceso de reflexión interna o al surgimiento de nuevas realidades sociales o cambios normativos (supuestos

41 Fuente: Memoria del Tribunal Constitucional del año 2015.

42 STC 56/2013, de 11 de marzo.

43 Vid., las SSTC 115/2013, de 9 de mayo; 29/2014, de 24 de febrero, y 170/2013, de 7 de octubre, respectivamente.

44 Determinar, en efecto, si la consolidada doctrina sobre emplazamiento se aplica a la Ley de la Jurisdicción Contencioso-Administrativa (STC 242/2012, de 17 de diciembre) o si las entidades bancarias pueden ceder datos de sus clientes a organizaciones de consumidores (STC 96/2012, de 7 de mayo) puede entenderse más como un supuesto que encaja mejor en la letra b) que en la letra a) del FJ 2.

45 Fuente: Memoria del Tribunal Constitucional del año 2015. 
estos mencionados en la STC 155/2009) ${ }^{46}$. En la mayor parte de supuestos la trascendencia constitucional se ha fundamentado sobre todo en la necesidad de aclarar — más que cambiar- la doctrina constitucional en supuestos sobre los que no existía un precedente claro. Así por ejemplo, se ha considerado necesario determinar si la doctrina sobre el planteamiento de la cuestión prejudicial era aplicable a un determinado supuesto, si el art. 23.2 CE era aplicable al acceso a un rectorado, si los partidos políticos son titulares del derecho al honor o si los farmacéuticos tienen derecho a la objeción de conciencia para dispensar la píldora del día después.

El uso que el Tribunal ha hecho de las letras a) y b) del FJ 2 ha sido, pues, amplio, sin que, por lo general, se haya diferenciado de forma nítida unos supuestos que en el plano teórico no son radicalmente distintos. Teniendo en cuenta el concepto de doctrina constitucional que maneja el Tribunal y que la especial trascendencia constitucional no predetermina el sentido estimatorio del fallo, desde una perspectiva material lo que parece determinante es el interés del Tribunal por entrar en el fondo de un asunto que no ha sido resuelto con anterioridad, sobre el que la doctrina constitucional es insuficiente (más que inexistente) o que ofrece una posibilidad de modificar o aclarar una doctrina preexistente. En definitiva, hasta ahora el Tribunal ha hecho una aplicación generosa y amplia de estos supuestos lo que le ha permitido emplearlos con gran libertad.

El supuesto contemplado en la letra c) del FJ 2 (que la vulneración provenga de una ley o disposición de carácter general) se ha confirmado hasta ahora en muchos menos scasos (seis en total, uno en 2015, esto es, en el $1,15 \%$ de las admisiones ${ }^{47}$ ). También aquí el Tribunal ha hecho una interpretación generosa del supuesto, al incluir entre las disposiciones de carácter general incluso una instrucción de un director de un centro penitenciario ${ }^{48}$. En todo caso, lo más destacado de la aplicación práctica de este supuesto ha sido la ya mencionada relativización de la carga de justificar la especial trascendencia constitucional. De hecho, resulta incluso forzado aludir a la flexibilidad

46 La Memoria del año 2015 sí incorpora información sobre este extremo: en el 11,49\% de los supuestos la aclaración o cambio doctrinal ha sido consecuencia de un proceso de reflexión interno, en el 2,29\% de cambios nuevas realidades sociales y en el $13,79 \%$ de cambios normativos.

47 SSTC 77/2013, 8 de abril; 116/2013, de 20 de mayo; 167/2013, de 7 de octubre; 118/2014, de 8 de julio; 128/2014, de 21 de julio; y 89/2015, de 11 de mayo. Respecto del año 2015, véase la Memoria del Tribunal Constitucional correspondiente a este año.

48 STC 15/2011, de 28 de febrero. 
con la que el Tribunal analiza el cumplimiento de dicha carga, puesto que la especial trascendencia del caso deriva de manera necesaria y directa del origen normativo de la lesión aducida. La aplicación práctica de la letra c) del FJ 2 de la STC 155/2009 ha puesto de relieve, pues, la rigidez de la doctrina constitucional en torno a la dimensión formal de la especial trascendencia constitucional o, lo que es lo mismo, la conveniencia de matizar la doctrina del Tribunal Constitucional en estos casos.

Por su parte, el supuesto contemplado en la letra d) del tantas veces mencionado FJ 2 (que la vulneración «traiga causa de una reiterada interpretación jurisprudencial de la ley que el Tribunal considere lesiva del derecho fundamental y crea necesario proclamar otra interpretación conforme de la Constitución») ha tenido una aplicación práctica mucho más discreta de lo que cabía esperar. Aunque existen dudas en torno a la propia delimitación del supuesto ${ }^{49}$, el único caso en que el Tribunal se ha referido de forma expresa a esta letra ha sido el de la STC 167/2013, de 7 de octubre. Hay que tener en cuenta, sin embargo, que en este caso el problema de constitucionalidad radicaba en el fondo en la norma del Código Civil que determina el orden de los apellidos en supuestos de reconocimiento judicial de la filiación, por lo cual también concurría la letra c) del FJ 2. Pero la alusión a la existencia de una interpretación jurisprudencial generalizada, que en el caso de los menores entraba en conflicto con el art. $18 \mathrm{CE}$, permitió al Tribunal afirmar la concurrencia del supuesto previsto en la letra d). En todo caso, se trata de un supuesto de especial trascendencia constitucional que se ha dado poco en la práctica.

Frente a ello, el Tribunal ha tenido ocasión de aclarar que el supuesto contemplado en la letra e) («incumplimiento general y reiterado de la doctrina constitucional por la jurisdicción ordinaria o existencia de resoluciones judiciales contradictorias sobre el derecho fundamental») tiene como finalidad proteger una doctrina constitucional ya existente. De los cinco casos en los que el Tribunal se ha refirido de manera expresa a este supuesto se deduce que este supuesto se da cuando la jurisdicción ordinaria incumple de una manera directa la doctrina constitucional o discrepa de su interpretación o aplicación. Así, el Tribunal Constitucional ha reaccionado frente a actuaciones judiciales contrarias a su doctrina sobre la intervención de las comunicaciones entre los internos de una prisión y los órganos de vigilancia penitenciaria, sobre la in-

49 La Memoria del Tribunal Constitucional hace referencia a la existencia de resoluciones judiciales contradictorias cuando la STC 155/2009 incluye este supuesto en la letra e) de su fundamento jurídico 2. Seguramente por ello se señala que en el año 2015 este supuesto se dio en 11 casos, un 12,65\% de las admisiones. 
admisión de los recursos de habeas corpus o sobre la inadmisión del incidente de nulidad de actuaciones.

Cabe destacar que la categoría de los órganos judiciales que se apartan de la doctrina constitucional resulta irrelevante para el Tribunal Constitucional. Es más, incluso se ha admitido que tal comportamiento provenga de un centro penitenciario si no ha sido corregido por los tribunales de instancia ${ }^{50}$. En todo caso, el Tribunal Constitucional sí ha insistido en el carácter general y reiterado de tal incumplimiento, si bien se ha aceptado como suficiente un incumplimiento limitado a una determinada demarcación territorial. ${ }^{51}$ Una vez más, pues, cabe constatar una interpretación amplia del supuesto ahora analizado, que en este caso deriva de una voluntad clara del Tribunal Constitucional de garantizar el carácter vinculante de su jurisprudencia.

Relacionado con esto último, cabe señalar que el Tribunal ha empleado diversos criterios para considerar acreditado el incumplimiento de su doctrina. En unos casos, se ha referido a la admisión a trámite de otras demandas de amparo sobre supuestos similares; en otros, a la existencia de un número relevante de sentencias constitucionales que han estimado recursos similares; y, en algún otro, incluso a la existencia de condenas a España por parte del Tribunal Europeo de Derechos Humanos en casos parecidos ${ }^{52}$. En definitiva, de lo que se trata a través de este supuesto es de defender la doctrina constitucional frente a incumplimientos no ocasionales de esta por la jurisdicción ordinaria.

Por su parte, el supuesto contemplado en la letra f) («negativa manifiesta del deber de acatamiento de la doctrina del Tribunal Constitucional por parte de un órgano judicial») se ha apreciado de momento en tres ocasiones, relativas a la negativa de determinados tribunales a aplicar la doctrina sobre el cómputo de la prescripción penal, y en un supuesto en que se había incumplido de forma deliberada una sentencia del Tribunal sobre la admisión a trá-

50 Vid., en este sentido, el ATC 165/2011, de 12 de noviembre, en el que se estima la súplica del fiscal planteada frente una providencia de inadmisión que se había basado no en un problema de justificación, sino de no concurrencia de la especial trascendencia constitucional. Se trata de uno de los pocos supuestos en que el Tribunal ha rectificado por motivos sustantivos una decisión inicial de inadmisión.

51 Vid., en este sentido, de nuevo el ATC 165/2011, de 12 de noviembre, que pretende hacer frente al incumplimiento en la provincia de Cádiz de la doctrina sobre la intervención de las comunicaciones entre los internos de un centro penitenciario y los órganos judiciales de vigilancia penitenciaria.

52 Vid., en este sentido, la STC 21/2014, de 10 de febrero; y los AATC 108/2014, de 7 de abril, y 123/2012, de 18 de junio. 
mite de una demanda arrendaticia ${ }^{53}$. En todos estos casos cabe destacar que la negativa manifiesta a seguir la doctrina constitucional se había vinculado con la existencia de una doctrina del Tribunal Supremo que se pretende imponer sobre la del Tribunal Constitucional. Aunque el desacato no provenía, por tanto, del Tribunal Supremo, la aplicación de este supuesto ha confirmado que el origen de la letra f) está muy vinculado a las tensiones que en algunos casos concretos y conocidos se han suscitado entre este Tribunal y el Tribunal Constitucional.

En todo caso, como se ha señalado de manera recurrente $e^{54}$, la errónea interpretación o inaplicación de la doctrina del Tribunal Constitucional no resulta suficiente para considerar cumplido el supuesto de la letra f), sino que es necesaria una «decisión consciente e intencional de soslayar la aplicación de la doctrina del Tribunal Constitucional», es decir, un «elemento intencional o volitivo".

Aunque no se ha planteado como en el supuesto de las lesiones de origen normativo, en el caso del desacato de la jurisprudencia constitucional cabe plantearse la necesidad de atemperar la carga del recurrente de justificar la trascendencia constitucional de su demanda. En este supuesto, en efecto, el papel de la demanda como un instrumento de colaboración con la jurisdicción constitucional es importante respecto del incumplimiento de la doctrina constitucional, pero no para determinar si dicho incumplimiento es expresión de una negativa manifiesta del deber de acatamiento. De hecho, resultaría muy improbable (y en buena medida criticable) que en un supuesto de este tipo, el recurso se inadmitiese por una deficiente justificación de la trascendencia. Es más, en las pocas sentencias en que se ha apreciado la concurrencia de la letra $\mathrm{f}$ ), la justificación de la trascendencia había sido claramente deficiente, aunque en los dos primeros el Tribunal la dio por buena con el argumento que las demandas habían sido interpuestas antes de la STC 155/2009. En todo caso, la práctica jurisprudencial en relación con este supuesto ha vuelto a poner de manifiesto que las dimensiones formal y material de la especial trascendencia constitucional pueden estar muy relacionadas, de manera que la segunda compensa los posibles déficits de la primera.

Como era de esperar, la aplicación del último supuesto del fundamento jurídico 2 de la STC 155/2009 («que el asunto suscitado, sin estar incluído en ninguno de los supuestos anteriores, plantee una cuestión jurídica de rele-

53 Vid., las SSTC 2/2013, de 14 de enero; 32/2013, de 11 de febrero; y 115/2015, de 8 de junio, respectivamente.

54 Vid., en este sentido, los AATC 26/2012, de 31 de enero; 42/2010, de 12 de abril; y 141/2012, de 9 de julio, así como la STC 115/2015, de 8 de junio. 
vante y general repercusión social o económica o tenga unas consecuencias políticas generales») ha planteado mayores problemas en la práctica. Su carácter expresamente supletorio y los términos empleados para describirlo confieren al supuesto de la letra g) un grado de indeterminación y discrecionalidad que es todavía mayor que en los supuestos anteriores. Ahora bien, la inmensa mayoría de los pronunciamientos donde este supuesto se ha apreciado corresponden a recursos de amparo electorales y, en menor medida, parlamentarios que no deberían plantear problemas, puesto que son mencionados en la propia letra g). En algunos casos, sin embargo, el Tribunal ha confirmado en súplica la inadmisión a trámite de recursos de amparo sobre la proclamación de candidatos a las elecciones municipales por falta de justificación de la especial trascendencia constitucional ${ }^{55}$. Es cierto que la propia letra g) del fundamento jurídido 2 de la STC 155/2009 no presupone la admisión a trámite de todos los recursos de amparo parlamentarios y electorales. Sin embargo, una interpretación rigorista de la carga de justificar la especial trascendencia constitucional en este tipo de supuestos no parece de recibo, puesto que no resulta compatible con el carácter materialmente constitucional —más que procesal- del concepto especial trascendencia constitucional.

Más allá de los amparos electorales o parlamentarios, en los últimos años también están apareciendo pronunciamientos que consideran que el supuesto de la letra g) concurría en recursos de amparo que impugnaban sentencias que habían anulado una disposición general ${ }^{56}$, que habían impedido la impugnación de un convenio colectivo ${ }^{57}$, así como en recursos que planteaban cuestiones tales como si un Estado concreto puede plantear extradiciones a España ${ }^{58}$ o si el procedimiento de ejecución hipotecaria es incompatible con determinados derechos fundamentales ${ }^{59}$. A modo de obiter dicta, también se ha aceptado la posibilidad de que las repercusiones económicas de la decisión recurrida puedan justificar la especial trascendencia del recurso con base en este supuesto (y no en base a una hipotética gravedad de la lesión como en el caso alemán $)^{60}$. La práctica jurisprudencial ha corroborado, pues, que el alcance potencial de este supuesto de especial trascendencia constitucional es amplio, si bien de momento no se ha empleado para introducir cambios significativos en el nuevo sistema de admisión.

\footnotetext{
55 Así, en los AATC 48, 49 y 50/2011, de 5 de mayo.

56 STC 183/2011, de 21 de noviembre.

57 STC 44/2013, de 25 de febrero.

58 STC 31/2013, de 11 de febrero.

59 STC 89/2013, de 8 de abril.

60 STC 56/2013, de 11 de marzo.
} 
En definitiva, como se ha visto en las páginas precedentes, el Tribunal Constitucional ha ido desarrollando y aplicando los diversos supuestos de especial trascendencia constitucional descritos en la STC 155/2009 desde una posición celosa de su monopolio para apreciar la concurrencia de este requisito material y sin prestar excesiva atención a la concreta justificación de sus decisiones. Es cierto que la jurisprudencia de los últimos años ha empezado a clarificar algunas cuestiones relativas a cada uno de los supuestos de especial trascendencia constitucional, y que esta tendencia seguro que se intensificará como consecuencia de la Sentencia del Tribunal Europeo de Derechos Humanos sobre el Asunto Arribas Antón contra España. No obstante, la aplicación práctica de la doctrina contenida en la STC 155/2009 ha puesto de relieve un interpretación generosa por parte del Tribunal Constitucional, una vinculación importante a la existencia de precedentes jurisprudenciales concretos y una influencia notable de la dimensión material de la especial trascendencia constitucional sobre su dimensión formal. Si bien es cierto que el Tribunal se ha referido en alguna ocasión a la conexión entre ambas dimensiones, la práctica de estos años ha realzado la necesidad de flexibilizar el requisito de la justificación de dicha trascendencia no solo según la fecha de interposición de la demanda, sino también según el supuesto concreto del fundamento jurídico 2 de la STC 155/2009 que otorga trascendencia al recurso.

\section{EL PAPEL DE LA VEROSIMILITUD DE LA LESIÓN ADUCIDA}

Si bien la gran novedad de la reforma del año 2007 fue la introducción de la especial trascendencia constitucional como un requisito de admisión y la consiguiente objetivación del recurso de amparo, uno de los grandes interrogantes de esta fue el papel que debía desempeñar la lesión del derecho fundamental invocado y, por tanto, la dimensión subjetiva del amparo. Como se ha señalado anteriormente, el equilibrio entre las dos dimensiones del recurso de amparo no se encuentra regulado de manera precisa en la normativa que regula al Tribunal Constitucional. Por su parte, entre los propios magistrados del Tribunal han existido diferencias claras en torno al papel que debía otorgarse a la dimensión subjetiva del amparo. Tales discrepancias se han traducido en ocasiones en votos particulares ${ }^{61} \mathrm{y}$ en algunas épocas en dudas sobre si la inexistencia de la lesión aducida constituía un supuesto de no concurrencia

61 Una vez más, cabe citar los votos particulares del magistrado Gay Montalvo al ATC 289/2008, de 22 de septiembre; y del magistrado Valdés Dal-Ré al ATC 28/2013, de 11 de febrero. 
de la especial trascendencia constitucional [art. 50.1.b) LOTC] o de incumplimiento de los demás requisitos de la demanda [art. 50.1.a) LOTC].

Como se ha visto, el Tribunal Constitucional ha insistido desde un principio en que la especial trascendencia constitucional de la demanda constituye un requisito distinto y autónomo de la lesión del derecho fundamental invocado. En esta misma línea, también ha señalado que la especial trascendencia se predica del recurso en su conjunto y no de cada una de las lesiones aducidas ${ }^{62}$. Pero en todo caso, el Tribunal Constitucional ha afirmado de manera expresa que el recurso de amparo sigue siendo un recurso de tutela de los derechos fundamentales $^{63}$ y cierra con ello las puertas a una objetivización absoluta de este.

El análisis de los pronunciamientos del Tribunal de los últimos años ha puesto de relieve, sin embargo, que la lesión del derecho fundamental ha ido teniendo un papel cada vez más relevante en la aplicación de la reforma hasta el punto de eclipsar el nuevo requisito de la especial trascendencia constitucional. Así, algunos pronunciamientos del Tribunal empezaron a referirse de manera rápida a la lesión aducida y, en concreto, a su verosimilitud como un presupuesto previo de la trascendencia constitucional y, por lo tanto, como un contenido del juicio de admisión ${ }^{64}$. Por otro lado, a pesar de haber señalado de manera expresa que la especial trascendencia constitucional debe desvincularse de la gravedad o notoriedad de la lesión aducida ${ }^{65}$, y que en nuestro país no rige un sistema como el alemán, en que la gravedad de una determinada violación puede hacerla automáticamente trascendente ${ }^{66}$, la aplicación práctica de la especial trascendencia constitucional ha estado muy influida por la verosimilitud de la lesión aducida, que, como se ha visto, ha condicionado la aplicación de la doctrina sobre la carga de justificar dicha trascendencia, así como sobre su contenido material. En definitiva, la tendencia, detectada de forma temprana por Requejo Pagés ${ }^{67}$ y denunciada también por González Alonso $^{68}$, de otorgar un peso relevante a la lesión del derecho fundamental invocado se ha confirmado de forma clara en los últimos años.

62 Vid., en este sentido, las SSTC 2/2013, de 14 de enero; y 46/2014, de 7 de abril.

64 Más allá de algunas providencias de inadmisión, este también fue el caso de algunos Autos que dieron respuesta a recuros de súplica del fiscal, en los que, a mayor abundamiento, se aludía a que la lesión aducida no era verosímil. Vid., a modo de ejemplo, el ATC 274/2009, de 30 de noviembre.

65 Vid., la STC 56/2013, de 11 de marzo; y el ATC 201/2010, de 21 de diciembre.

66 ATC 29/2011, de 17 de marzo.

67 Requejo Pagés (2012: 291 y ss.).

68 Vid., González Alonso (2013: 28 y 37 y ss.). 
Una prueba evidente de este hecho la ofrecen las dos últimas memorias del Tribunal Constitucional, que han introducido un nuevo cuadro estadístico sobre los motivos de inadmisión de los recursos de amparo. Pues bien, resulta ilustrativo comprobar que la inexistencia de vulneración del derecho fundamental invocado fundamenta más de un tercio de todas las decisiones de inadmisión, mientras que otro tercio se basa en problemas de justificación de la especial trascendencia constitucional y menos de un $1 \%$ de tales decisiones aprecia la no concurrencia material de este requisito ${ }^{69}$.

El modo en que se está aplicando la reforma ha supuesto, pues, la subsistencia, en un tercio de los supuestos, de unas providencias de inadmisión muy parecidas (por lo menos desde un punto de vista material) a las antiguas providencias de inadmisión por una carencia manifiesta de contenido constitucional del art. 50.1.c) LOTC, a pesar de que este precepto fue derogado por la reforma de 2007. Eso sí, a diferencia de la práctica anterior del Tribunal, estas providencias no se motivan, sino que se limitan a especificar el requisito incumplido, esto es, señalan que la lesión no ha existido.

Semejante práctica plantea el eterno problema de anticipar cierto juicio de fondo en la fase de admisión. En la medida en que la calidad del amparo no parece haber mejorado en los últimos años, ello puede resultar justificado en la mayor parte de supuestos. Sin embargo, cabe llamar la atención sobre el peligro de resolver en la fase de admisión aquellos problemas que tienen una trascendencia constitucional clara, a pesar de que la lesión invocada sea dudosa. Un buen ejemplo en este sentido lo constituye el ATC 9/2012, de 13 de enero, relativo a la tramitación parlamentaria de la reforma constitucional del art. $135 \mathrm{CE}$, en el que se inadmitió a trámite un recurso de amparo parlamentario con el argumento de la manifiesta inexistencia de un derecho fundamental tutelable en amparo. Sin entrar en el fondo del recurso planteado, esta forma de proceder no solo plantea un problema de "construcción procesal», por emplear los términos utilizados por el magistrado Pérez Tremps en su voto particular a dicho Auto, sino que revela una aplicación de la reforma del año 2007 que es tributaria del régimen de admisión anterior, basado sobre todo en

69 En concreto, la inexistencia de vulneración del derecho fundamental invocado motivó el $31 \%$ de las decisiones de inadmisión en el año 2014 y el 36,92 \% de estas decisiones en el año 2015; la falta de justificación de la especial trascendencia constitucional fundamentó el 19,97\% de las decisiones de inadmisión en 2014 y el 16,57 \% en el año 2015; y la insuficiente justificación dicha trascendencia motivó el 16,27 \% de las decisiones de inadmisión en 2014 y el 19,60 \% en 2015. Por contra, solo el 0,25\% de las decisiones de inadmisión se basaron en la falta de especial trascendencia constititucional en 2014, mientras que en 2015 dicho porcentaje llegó al 0,78 \%. 
el carácter subjetivo del recurso de amparo. En el caso que nos ocupa es cierto que la inexistencia de la lesión se motivó al tratarse de un auto, pero la posibilidad que supuestos de clara trascendencia constitucional (aplicando los criterios del propio Tribunal) no sean examinados sobre la base de una inexistente vulneración del derecho fundamental aducido debería descartarse, puesto que en casos es muy difícil (por no decir imposible) que la inexistencia de la vulneración sea evidente.

\section{CONCLUSIONES}

La introducción, en el año 2007, del concepto especial trascendencia constitucional en la Ley Orgánica del Tribunal Constitucional ha constituido, sin duda, el cambio más relevante experimentado por la regulación legal del recurso de amparo desde su creación. Mediante la inversión del juicio de admisión y la introducción de una nueva causa positiva de admisión se pretendió, sobre todo, redimensionar el volumen de trabajo del Tribunal y mejorar los tiempos de resolución de la jurisdicción constitucional española.

Transcurridos siete años desde la entrada en vigor de dicha reforma, sus objetivos pueden considerarse cumplidos. Los recursos de amparo pendientes de admisión se han reducido un $76 \%$, los amparos pendientes de sentencia han disminuído en un $68 \%$ y los asuntos de Pleno pendientes de sentencia han descendido un $64 \%$. Aunque en los últimos años alguna de estas tendencias se ha invertido ligeramente, el recurso de amparo se ha puesto casi al día y los asuntos de Pleno pendientes se han reducido de manera significativa, si bien todavía no suficiente.

La reforma puede haber contribuido de una manera indirecta a la reducción de la demanda de amparo (que ha disminuído en un tercio), pero no parece haber propiciado ningún cambio significativo ni en la calidad del amparo que se reclama, ni en los derechos que se pretenden tutelar. Es cierto que ninguna de estas dos cuestiones estaba entre los objetivos de la reforma. Pero la demanda de amparo de estos últimos años ha seguido demostrando que es necesario introducir reformas (no necesariamente en la Ley Orgánica del Tribunal Constitucional) que permitan reducir la llegada de amparos de baja calidad, que en el fondo plantean problemas que son de legalidad ordinaria o de simple discrepancia con pronunciamientos judiciales previos.

Más allá de la dimensión cuantitativa del amparo (que no debe, por otro lado, despreciarse), cabe destacar que el Tribunal Constitucional ha aplicado la reforma del año 2007 de manera progresiva y meditada. Ahora bien, algunos aspectos de dicha aplicación no parecen coherentes con la naturaleza constitucional de su jurisdicción. Así, la relevancia otorgada a la carga de jus- 
tificar la especial trascendencia constitucional de las demandas de amparo y la incertidumbre que ha existido en torno a lo que constituye una justificación suficiente se compadecen mal con una jurisdicción constitucional centrada en la resolución de casos que plantean problemas sustantivos sobre el contenido $\mathrm{y}$ alcance de los derechos fundamentales. Superado el desconocimiento inicial de los abogados en relación con el contenido de la reforma, parecería más adecuado que la carga de justificar la especial trascendencia constitucional pasase a un segundo plano.

Por su parte, el esfuerzo por dar a conocer (con cierto retraso) los criterios interpretativos del nuevo régimen de admisión no ha impedido que el Tribunal los haya aplicado desde una concepción celosa por reivindicar y defender el monopolio del control sobre el concepto especial trascendencia constitucional. El Tribunal es, en efecto, el dueño de un concepto que también contribuyó a crear. En todo caso, durante todos estos años el Tribunal ha administrado dicho concepto y los supuestos enumerados en el fundamento jurídico 2 de la STC 155/2009 desde una interpretación generosa, pero también desde una posición muy celosa de la jurisdicción constitucional y una concepción de la doctrina constitucional que se desea crear, modificar o aclarar muy ligada al precedente.

Al mismo tiempo, la jurisprudencia de los últimos años ha puesto de relieve la rigidez de la doctrina inicial del Tribunal en relación con la necesidad de diferenciar las dimensiones formal y material de la especial trascendencia constitucional. Más allá de la flexibilización de la dimensión formal en función del momento de interposición de la demanda, la práctica jurisprudencial ha puesto de manifiesto que, en determinados casos (por ejemplo, cuando la lesión tiene un origen normativo o cuando existe un desacato manifiesto de la jurisprudencia constitucional), dicha trascendencia concurre al margen de su justificación formal y que la demanda de amparo difícilmente puede resultar un instrumento útil para el Tribunal en el momento de apreciarla.

Pero el aspecto sin duda más destacado de la aplicación de la reforma del amparo durante todos estos años ha sido la relevancia que ha seguido dándose a la lesión del derecho fundamental invocado. La verosimilitud e importancia de la lesión han condicionado, en efecto, de manera importante la aplicación de la doctrina sobre la carga de justificar la especial trascendencia constitucional de las demandas de amparo, así como la doctrina sobre el contenido material de dicha trascendencia. Al margen de los pronunciamientos generales sobre la figura de la especial trascendencia constitucional, su aplicación práctica ha puesto de relieve, en definitiva, que la probabilidad y gravedad de la lesión aducida han desempeñado un papel destacado en el momento de controlar el cumplimiento de los requisitos derivados de ella. Así, cuando el Tri- 
bunal ha considerado necesario entrar a conocer un asunto por la gravedad de la lesión aducida, se ha hecho una interpretación generosa de la carga de justificar la especial trascendencia constitucional y de los supuestos en que esta concurre para hacerlo posible.

Pero además, la falta de lesión del derecho fundamental aducida ha resurgido como criterio autónomo de inadmisión hasta el punto que, en los ultimos años, un tercio de las providencias de inadmisión se basan en la inexistencia de la vulneración invocada. La resurrección, de algún modo, de las antiguas providencias de inadmisión por una manifiesta carencia de contenido constitucional ha venido, pues, a desplazar o eclipsar la figura de la especial trascendencia constitucional, a pesar de que la reforma del año 2007 le otorgó un papel central.

$\mathrm{Si}$ a ello se añade que la jurisprudencia constitucional ha otorgado una gran importancia a la dimensión formal de la especial trascendencia constitucional, de modo que un tercio de las providencias de inadmisión se basan en su insuficiente justificación, no cabe sino concluir constatando que el cambio trascendental del régimen de admisión operado por la Ley Orgánica 6/2007 ha sido en buena medida contrarrestado por una aplicación jurisprudencial de la reforma que es tributaria de una concepción sobre todo subjetiva del amparo, que no era la predominante ni en el momento de aprobarse la reforma, ni en el Tribunal Constitucional que la impulsó.

\section{Bibliografía}

Borrajo Iniesta, I. (2008). Mitos y realidades de la jurisdicción constitucional de amparo: hechos, Derecho, pronunciamientos, admisión, coste. Teoría y Derecho: Revista de Pensamiento jurídico (3), 159-203.

Borrajo Iniesta I. y Elías Méndez, C. (2009). La puesta en marcha del nuevo recurso de amparo y otras facetas de la jurisprudencia constitucional. Revista General de Derecho Constitucional (8), 1-25.

Cabañas García, J. C. (2010). El recurso de amparo que queremos (Reflexiones a propósito de la Ley Orgánica 6/2007, de 24 de mayo, de reforma pacial de la Ley Orgánica del Tribunal Constitucional. Revista Española de Derecho Constitucional (88), 39-81.

Carrillo López, M. (2008). Hacia una nueva jurisdicción constitucional. Estudios sobre la Ley 6/2007, de 24 de mayo, de reforma de la LOTC. Valencia: Tirant lo Blanch.

González Alonso, A. (2013). ¿¿Ha cambiado algo el recurso de amparo español tras la aprobación de la LO 6/2007, de 24 de mayo? Justicia Administrativa (59), 17-40.

Hernández Ramos, M. (2010). ¿Admisión discrecional de los recursos de amparo por el Tribunal Constitucional? Balance de cuatro años de aplicación del nuevo trámite de admisión», Revista de las Cortes Generales (81), 263-283.

Pérez Tremps, P. (2015). El recurso de amparo. Valencia: Tirant lo Blanch. 
Requejo Pagés, J.L. (2012). Doctrina del Tribunal Constitucional durante el primer cuatrimestre de 2011. Revista Española de Derecho Constitucional (94), 289-334.

Urías Martínez, J. (2014). Seleccionar lo (menos) importante. En J. M. Morales Arroyo (dir.). Recurso de amparo, derechos fundamentales y trascendencia constitucional. El camino hacia la objetivación del amparo constitucional en España (pp. 73-94). Cizur Menor: Thomson Reuters Aranzadi.

VV. AA. (2006). Encuesta sobre la reforma de la Ley Orgánica del Tribunal Constitucional. Teoría y Realidad Constitucional (18), 38-57. 
